\title{
Bi Nanoparticles Anchored in N-Doped Porous Carbon as Anode of High Energy Density Lithium Ion Battery
}

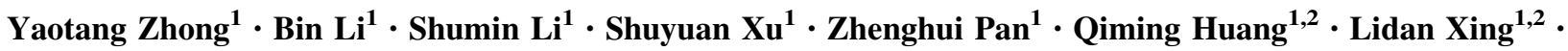 \\ Chunsheng Wang ${ }^{3} \cdot$ Weishan $\mathrm{Li}^{1,2}$
}

Received: 23 March 2018/ Accepted: 10 May 2018/Published online: 8 June 2018

(C) The Author(s) 2018

\section{Highlights}

- The Bi nanoparticles anchored in N-doped porous carbon (Bi@NC) composite was prepared by a facile replacement reaction method, in which ultrasmall Bi nanoparticles were homogeneously encapsulated in the carbon matrix

- The N-doped carbon matrix enhanced the electric conductivity and alleviated the mechanical strain of Bi nanoparticles on $\mathrm{Li}$ insertion/extraction due to the larger void space, and Bi@NC exhibits excellent cyclic stability and rate capability for LIBs

- The strategy developed in this work solves the cyclic instability issue of bismuth as anode for LIBs and provides a new approach to improve high volumetric energy density for electrochemical energy storage devices.

\begin{abstract}
A novel bismuth-carbon composite, in which bismuth nanoparticles were anchored in a nitrogen-doped carbon matrix (Bi@NC), is proposed as anode for high volumetric energy density lithium ion batteries (LIBs).
\end{abstract}

Electronic supplementary material The online version of this article (https://doi.org/10.1007/s40820-018-0209-1) contains supplementary material, which is available to authorized users.

$\triangle$ Chunsheng Wang

cswang@umd.edu

$\triangle$ Weishan Li

liwsh@scnu.edu.cn

1 School of Chemistry and Environment, South China Normal University, Guangzhou 510006, People's Republic of China

2 Engineering Research Center of MTEES (Ministry of Education), Research Center of BMET (Guangdong Province), Engineering Laboratory of OFMHEB (Guangdong Province), Key Laboratory of ETESPG (GHEI), and Innovative Platform for ITBMD (Guangzhou Municipality), South China Normal University, Guangzhou 510006, People's Republic of China

3 Department of Chemical and Bimolecular Engineering, University of Maryland, College Park, College Park, MD 20740, USA

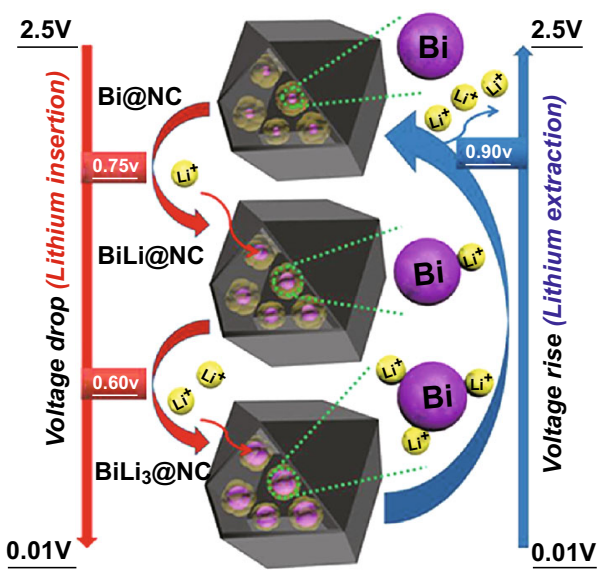

$\mathrm{Bi} @ \mathrm{NC}$ composite was synthesized via carbonization of Zn-containing zeolitic imidazolate (ZIF-8) and replacement of $\mathrm{Zn}$ with $\mathrm{Bi}$, resulting in the $\mathrm{N}$-doped carbon that was hierarchically porous and anchored with Bi nanoparticles. The matrix provides a highly electronic conductive network that facilitates the lithiation/delithiation of $\mathrm{Bi}$. Additionally, it restrains aggregation of Bi nanoparticles and serves as a buffer layer to alleviate the mechanical strain of $\mathrm{Bi}$ nanoparticles upon $\mathrm{Li}$ insertion/extraction. 
With these contributions, Bi@NC exhibits excellent cycling stability and rate capacity compared to bare $\mathrm{Bi}$ nanoparticles or their simple composites with carbon. This study provides a new approach for fabricating high volumetric energy density LIBs.

Keywords Porous N-doped carbon - Bi nanoparticles . Anode $\cdot$ Lithium-ion battery $\cdot$ High energy density

\section{Introduction}

Power sources with high volumetric and gravimetric energy densities are urgently needed to meet the small size and long service life requirements of various applications from information technology to transportation [1-6]. Lithium-ion batteries (LIBs) are the dominant power sources for these applications owing to their superior energy densities and cycle lives compared to other secondary batteries, but their energy densities are still unsatisfactory for quickly developing society [7-11].

Graphite is the most commonly used anode in commercial LIBs because of its superior cycling stability and high coulombic efficiency. However, the low theoretical capacity of the graphitic anode $\left(372 \mathrm{mAh} \mathrm{g}^{-1}\right)$ limits the development of graphite-based LIBs. Therefore, it is necessary to look for high energy density LIBs anodes.

Several metals including $\mathrm{Al}, \mathrm{Si}, \mathrm{Sn}, \mathrm{Sb}, \mathrm{Ge}$, and $\mathrm{Bi}$ have captured attention as anode materials due to their high theoretical capacities compared to graphite, which has been used as anode since the invention of LIBs. Al, Si, Sn, Sb, and Ge have far higher theoretical gravimetrical capacities than that of graphite $\left(372 \mathrm{mAh} \mathrm{g}^{-1}\right)$ through the formation of LiAl $\left(994 \mathrm{mAh} \mathrm{g}^{-1}\right), \mathrm{SiLi}_{4.4}\left(4200 \mathrm{mAh} \mathrm{g}^{-1}\right), \mathrm{SnLi}_{4.4}$ $\left(993 \mathrm{mAh} \mathrm{g}^{-1}\right), \quad \mathrm{SbLi}_{3}\left(660 \mathrm{mAh} \mathrm{g}^{-1}\right)$, and $\mathrm{Li}_{2.2} \mathrm{Ge}_{5}$ $\left(1600 \mathrm{mAh} \mathrm{g}^{-1}\right)$, but cannot give correspondingly high volumetric capacities, which is only respective 1383,2190 , 1991, 1889, and $2180 \mathrm{mAh} \mathrm{cm}^{-3}$ compared to $756 \mathrm{mAh} \mathrm{cm} \mathrm{c}^{-3}$ of graphite $[12,13]$. Besides, these metals yield potential hysteresis of $0.26,0.25,0.14,0.19$, and $0.21 \mathrm{~V}$ for lithiation/delithiation, respectively, which are not only larger than in graphite $(0.11 \mathrm{~V})$, but also are energy inefficient [1]. Although $\mathrm{Bi}$ is a diagonal element of $\mathrm{Sn}$ and in the same group as $\mathrm{Sb}$, it has unique layered crystal structure that can provide larger interlayer spacing to accommodate $\mathrm{Li}$ ions (such as $\mathrm{Li}_{3} \mathrm{Bi}$ ) [14-16]. Most importantly, bismuth gives a volumetric capacity of $3430 \mathrm{mAh} \mathrm{cm}^{-3}$, which is far higher than those of other metal anodes and about five-bold than that of graphite [17]. It also yields potential hysteresis the same as graphite [18] although its specific capacity $\left(385 \mathrm{mAh} \mathrm{g}^{-1}\right.$ ) is not so high, as shown in Fig. 1. These features of bismuth make LIBs attractive in applications where high volumetric energy densities are required [19-21].

Like other metal anodes, however, bismuth exhibits poor cycling stability due to its large volume change during lithiation/delithiation [1]. Some efforts have been made to solve this problem. For example, Park et al. [21] prepared a nanostructured Bi@C composite that delivered a relatively high capacity of $300 \mathrm{mAh} \mathrm{g}^{-1}$ after 100 cycles at current density $100 \mathrm{~mA} \mathrm{~g}^{-1}$ by varying the voltage from 0.0 to 2.0 V. Yang et al. [22] revealed that Bi@C microspheres as anode materials for LIBs retained capacity of $280 \mathrm{mAh} \mathrm{g}^{-1}$ after 100 cycles at current density $100 \mathrm{~mA} \mathrm{~g}^{-1}$. The improved cycling stability of bismuth in these efforts can be attributed to the controlled coating of carbon layer on bismuth, which enhances electronic conductivity and alleviates the mechanical strain of bismuth during lithiation/delithiation [23, 24]. Moreover, the controlled coating of carbon layer acts as host to stabilize the solid electrolyte interphase (SEI) on the bismuth surface [25]. However, the above-mentioned achievements are unsatisfactory for the practical application of bismuth as anode in LIBs.

Various carbon materials have been extensively studied for performance improvement of anode or cathode materials in LIBs [26-30]. Metal organic frameworks (MOFs) characterized by diverse skeletal structures, high surface areas, tunable pore sizes, and open metal sites in the skeleton have been demonstrated as promising templates or precursors for fabricating nanostructured carbon for various applications [31-37]. Except for the advantages mentioned above, MOFs can also be designed and synthesized in a straightforward and cost-effective manner by

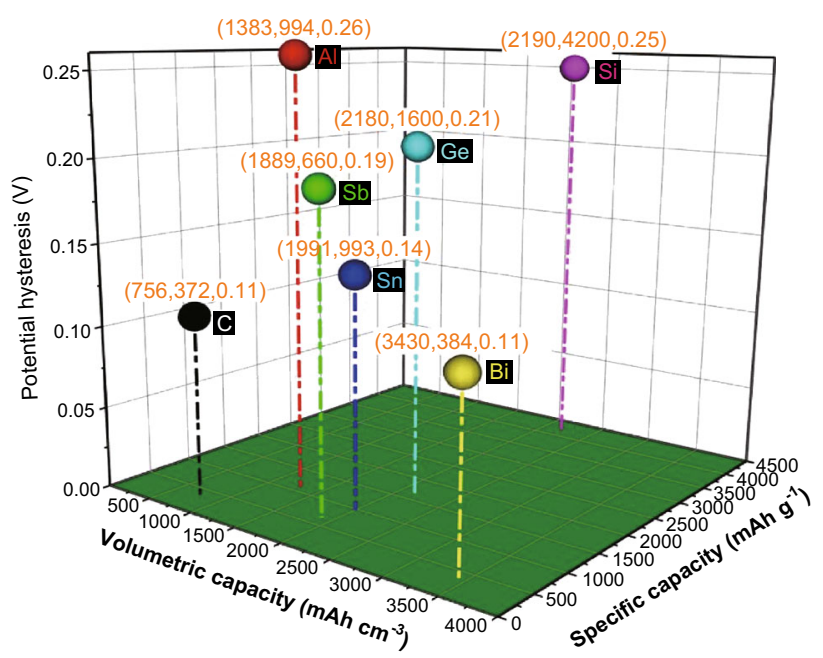

Fig. 1 Lithium storage performances of various metals in comparison to graphite 
assembling varied metal ions/clusters and organic ligands under mild conditions [38]. Therefore, without any processing equipment, it can be simply mass-produced just by increasing the amounts of raw materials. In addition, it has been noted that nitrogen-containing MOFs yield nitrogendoped carbon that exhibits enhanced electronic conductivity and activity toward reactions on carbon [39, 40]. Zeolitic imidazolate framework (ZIF-8), a kind of nitrogencontaining MOFs, combines high stability of inorganic zeolite with high surface area and porosity, and is a good precursor for preparing carbon matrices to enhance cycling stability of some electrode materials for LIBs [41-43]. For example, Si@ZIF8 composites were prepared by Han et al. [44] via in situ mechanochemical synthesis, which shows superior electrochemical properties with lithium storage capacity up to $1050 \mathrm{mAh} \mathrm{g}^{-1}$ and excellent cycle stability (>99\% capacity retention after 500 cycles).

In this work, a novel carbon/bismuth composite is introduced through a novel synthetic strategy wherein ZIF8 was used as precursor for $\mathrm{N}$-doped porous carbon to improve the cycling stability of the bismuth anode. ZIF-8 was obtained by a simple hydrothermal method at low temperature and underwent pyrolysis in $\mathrm{H}_{2} / \mathrm{Ar}$ atmosphere to form $\mathrm{N}$-doped porous carbon with dispersed zinc nanoparticles. Based on the potential difference between redox couples of $\mathrm{Zn}^{2+} / \mathrm{Zn}\left(-0.76 \mathrm{~V}\right.$ vs. SHE) and $\mathrm{Bi}^{3+} / \mathrm{Bi}$ $(0.31 \mathrm{~V})$ [45], bismuth nanoparticles were anchored on the carbon matrix through a replacement reaction. The carbon matrix afforded an electronically conductive network and served as support to restrain the aggregation of bismuth nanoparticles [46]. Most importantly, the pores in the carbon matrix provided space to alleviate the mechanical strain of bismuth during lithiation/delithiation. With these features, the resultant carbon/bismuth composite exhibited excellent performance as anode for LIBs when compared to other bismuth anodes that have been reported in other literatures.

\section{Experimental Section}

\subsection{Sample Syntheses}

ZIF-8 was synthesized hydrothermally [26]. Typically, 3 mmol zinc nitrate hexahydrate $\left(\mathrm{Zn}\left(\mathrm{NO}_{3}\right)_{2} \cdot 6 \mathrm{H}_{2} \mathrm{O}, 99 \%\right)$ and $8 \mathrm{mmol}$ 2-methylimidazole (MeIm, 98\%) were separately dispersed in $40 \mathrm{~mL}$ methanol $(99.5 \%)$ with moderate magnetic stirring for $10 \mathrm{~min}$ and then mixed under stirring for another $30 \mathrm{~min}$ at room temperature. The mixture was sealed in a Teflon-lined autoclave and maintained at $100{ }^{\circ} \mathrm{C}$. After a certain period of time, a white precipitate was harvested by centrifugation at $8000 \mathrm{rpm}$ for $3 \mathrm{~min}$, thoroughly washed with methanol, followed by drying in a vacuum oven overnight.

To obtain N-doped porous carbon with dispersed zinc nanoparticles (Zn@NC), carbonization process was carried out. The as-obtained ZIF-8 was heated at 500, 600, 700, and $800{ }^{\circ} \mathrm{C}$ for $3 \mathrm{~h}$ at the rate $2{ }^{\circ} \mathrm{C} \mathrm{min}{ }^{-1}$ under $\mathrm{H}_{2} / \mathrm{Ar}$ atmosphere with slow flow. Finally, a tan product was produced after high temperature calcination.

Bismuth nanoparticles were anchored in $\mathrm{N}$-doped porous carbon matrices by galvanic replacement reaction. Typically, $1 \mathrm{mmol}$ as-obtained $\mathrm{Zn} @ \mathrm{NC}$ and $1 \mathrm{mmol} \mathrm{BiCl}_{3}$ were homogeneously dispersed in $75 \mathrm{~mL}$ mixed solvent of glycerin and methanol (2:1 in volume) under ultrasonic treatment at room temperature for $30 \mathrm{~min}$. The mixture was sealed in a $100 \mathrm{~mL}$ Teflon-lined autoclave, maintained at $120^{\circ} \mathrm{C}$ for a certain period of time and then cooled naturally. To obtain the product $(\mathrm{Bi} @ \mathrm{NC})$, the precipitation was thoroughly washed with methanol via centrifugation-redispersion cycles at $9000 \mathrm{rpm}$ for $5 \mathrm{~min}$ and finally dried in a vacuum oven overnight.

The NC sample was obtained by washing Zn@NC with dilute $\mathrm{HCl}$ and then deionized water several times to remove the residual $\mathrm{Zn}$ component.

For performance comparison, Bi nanospheres (bare Bi, Beijing Dekedao, 99.95\%, OD $100 \mathrm{~nm}$ ) were used and a bismuth/carbon composite (Bi@C) was prepared hydrothermally by coating $\mathrm{Bi}$ nanospheres with carbon. Typically, $0.63 \mathrm{~g}$ Bi nanospheres were dispersed in $15 \mathrm{~mL}$ deionized water, which was mixed with $48 \mathrm{~mL}$ aqueous solution containing $1.8 \mathrm{~g}$ glucose. Methanol $(15 \mathrm{~mL})$ was added under stirring at room temperature for $15 \mathrm{~min}$. The mixture was then sealed in a $100 \mathrm{~mL}$ Teflon-lined autoclave and heated at $190{ }^{\circ} \mathrm{C}$ for $15 \mathrm{~h}$. After cooling naturally, the precipitate harvested as $\mathrm{Bi} @ \mathrm{NC}$ was prepared. Finally, the product $\mathrm{Bi} @ \mathrm{C}$ was obtained by heating the precipitate at $550{ }^{\circ} \mathrm{C}$ for $3 \mathrm{~h}$ under $\mathrm{N}_{2}$ at the rate $2{ }^{\circ} \mathrm{C} \min ^{-1}$.

\subsection{Physical Characterizations and Electrochemical Measurements}

The crystal configurations and crystallographic planes of the synthetic materials were identified by X-ray diffractometry (XRD, Ultima IV Germany). The specific surface area and pore diameter distribution were tested at liquid nitrogen temperature $(77 \mathrm{~K})$ with a surface area and porosimetry analyzer (V-Sorb 2800P). Scanning electron microscopy (SEM, JEOL JSM-6380LA) and transmission electron microscopy (TEM, JEOL JEM-2100HR) were carried out to observe the morphologies, structures, and particle sizes of the samples. During SEM observation, energy dispersion spectrum (EDS) and EDS mapping were also obtained. Fourier transition infrared (FTIR) spectrum 
of ZIF-8 was determined using infrared spectroscopy (Bruker Tensor 27) within $500-4000 \mathrm{~cm}^{-1}$. X-ray photoelectron spectrometer (XPS, Thermo Fisher Scientific, UK) was used with monochromatic Al-K $\alpha$ X-ray source (excitation energy $=1468.6 \mathrm{eV}$ ) under ultra-high vacuum (lower than $5 \times 10^{-8}$ mbar). Spectra were collected from 0 to $1350 \mathrm{eV}$ using an X-ray spot size of $400 \mu \mathrm{m}$ with pass energy $100 \mathrm{eV}$ for wide scan and $30 \mathrm{eV}$ for individual elements. Binding energies were corrected based on the carbon $1 s$ signal at $284.8 \mathrm{eV}$. Raman spectra were examined on an Alpha 300R Raman instrument at room temperature. The apparent densities of the samples were obtained by keeping the samples in a volumetric cylinder and then vibrating the cylinder until the volumes of the samples remained unchanged.

The Bi electrodes were composed of active materials, bare Bi, Bi@C or Bi@NC, acetylene black, and PVDF in the ratio $7: 1.5: 1.5$ by mass, which were mixed in $N$-methyl pyrrolidone and coated on $\mathrm{Cu}$ foil $\left(S=1.13 \mathrm{~cm}^{2}\right)$ with the weight of active materials being about $0.5 \mathrm{mg}$. CR2025 type coin cells were assembled with $\mathrm{Bi}$ electrode, lithium foil electrode, electrolyte of $1.0 \mathrm{M} \mathrm{LiPF}_{6}$ in ethyl methyl carbonate (EMC)/ethylene carbonate (EC)/diethyl carbonate $(\mathrm{DEC})(\mathrm{EMC} / \mathrm{EC} / \mathrm{DEC}=5: 3: 2$, by weight $)$, and a microporous membrane (Celgard 2400), in an Ar-filled glove box (Vigor-CH) where water and oxygen contents were controlled to less than $0.1 \mathrm{ppm}$.

The assembled coin cells were patiently tested on a multi-channel battery tester (LAND CT2001A, Wuhan, China) at $25{ }^{\circ} \mathrm{C}$ by discharging to $0.01 \mathrm{~V}$ and charging to $2.5 \mathrm{~V}$ at various current rates. Under certain operation conditions, cyclic voltammetry (CV) was collected from multichannel potentiostats (Bio-Logic SAS VMP-3) at scan rate $0.1 \mathrm{mV} \mathrm{s}^{-1}$. The electrochemical impedance spectroscopy of coin cells was carried out on an Autolab (PGSTAT302N) with AC signal $10 \mathrm{mV}_{\mathrm{rms}}$ from $0.1 \mathrm{MHz}$ to $0.01 \mathrm{~Hz}$.

\section{Results and Discussion}

The synthetic route for Bi@NC is depicted in Fig. 2. ZIF-8 was used as precursor and Zn@NC was obtained via carbonization of ZIF-8 under $\mathrm{H}_{2} / \mathrm{Ar}$. The polyhedral morphology of ZIF was maintained and the skeleton was composed of nitrogen-doped carbon. The $\mathrm{Zn}^{2+}$ ions in the ZIF-8 precursor were transformed to $\mathrm{Zn}$ nanoparticles under the effect of pyrolytic carbon as reducing agent. A galvanic replacement reaction took place, when $\mathrm{Bi}^{3+}$ ions were introduced. This enabled the $\mathrm{Bi}$ nanoparticles to replace $\mathrm{Zn}$ nanoparticles in situ, resulting in a special configuration of $\mathrm{Bi}$ nanoparticles anchored in the skeleton of nitrogen-doped porous carbon. This configuration provided the resulting $\mathrm{Bi} @ \mathrm{NC}$ with advantages of highly active Bi nanoparticles, electronically conductive $\mathrm{NC}$, and $\mathrm{Li}$ insertion/extraction volume buffering porous structure.

The synthesized ZIF-8 was characterized with XRD, FTIR, and SEM. Figure 3a presents the XRD pattern of ZIF-8 precursor, compared with simulated ZIF-8 [47-49]. It can be clearly seen from Fig. 3a that all diffraction peak intensities and shapes of synthesized ZIF-8 are identical to the simulated ZIF-8, indicating high crystallinity and purity

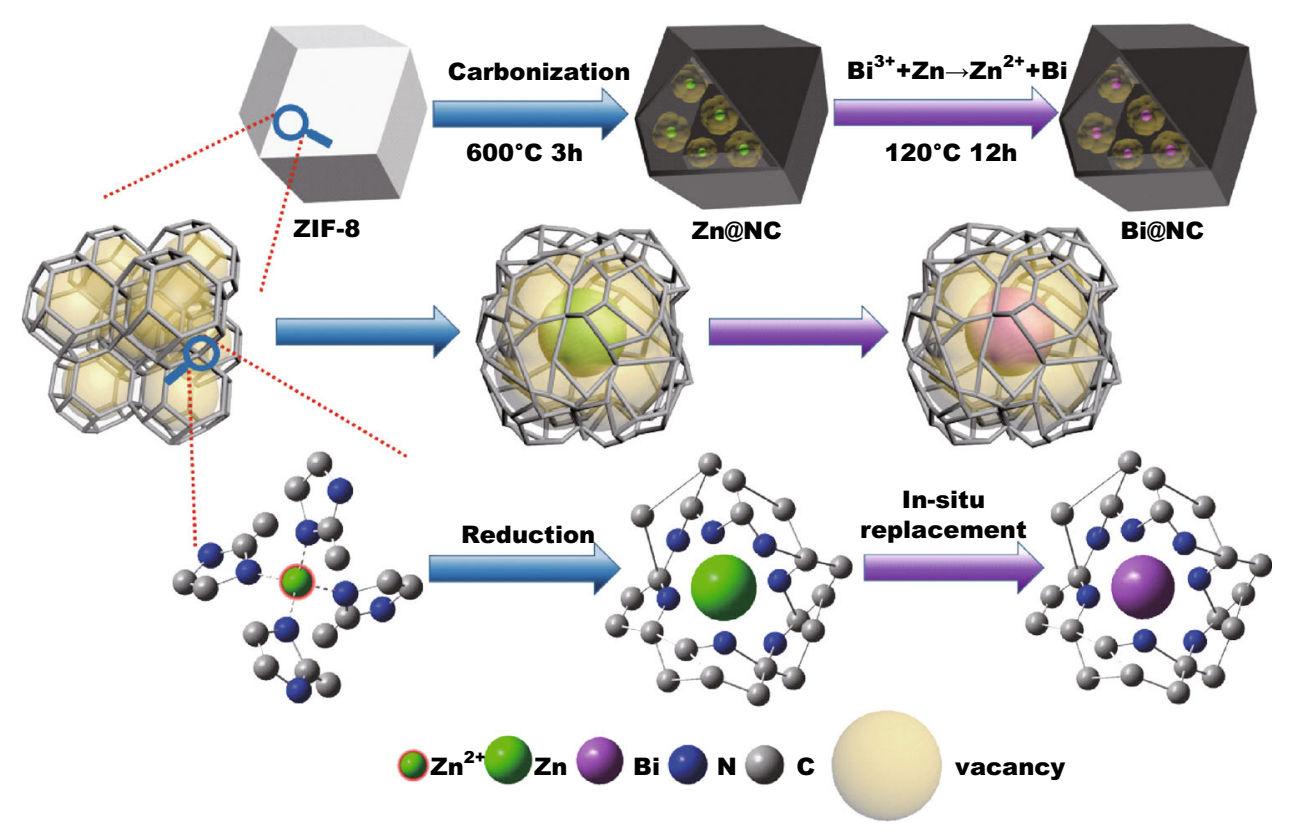

Fig. 2 Schematic illustration of the formation process of Bi@NC 

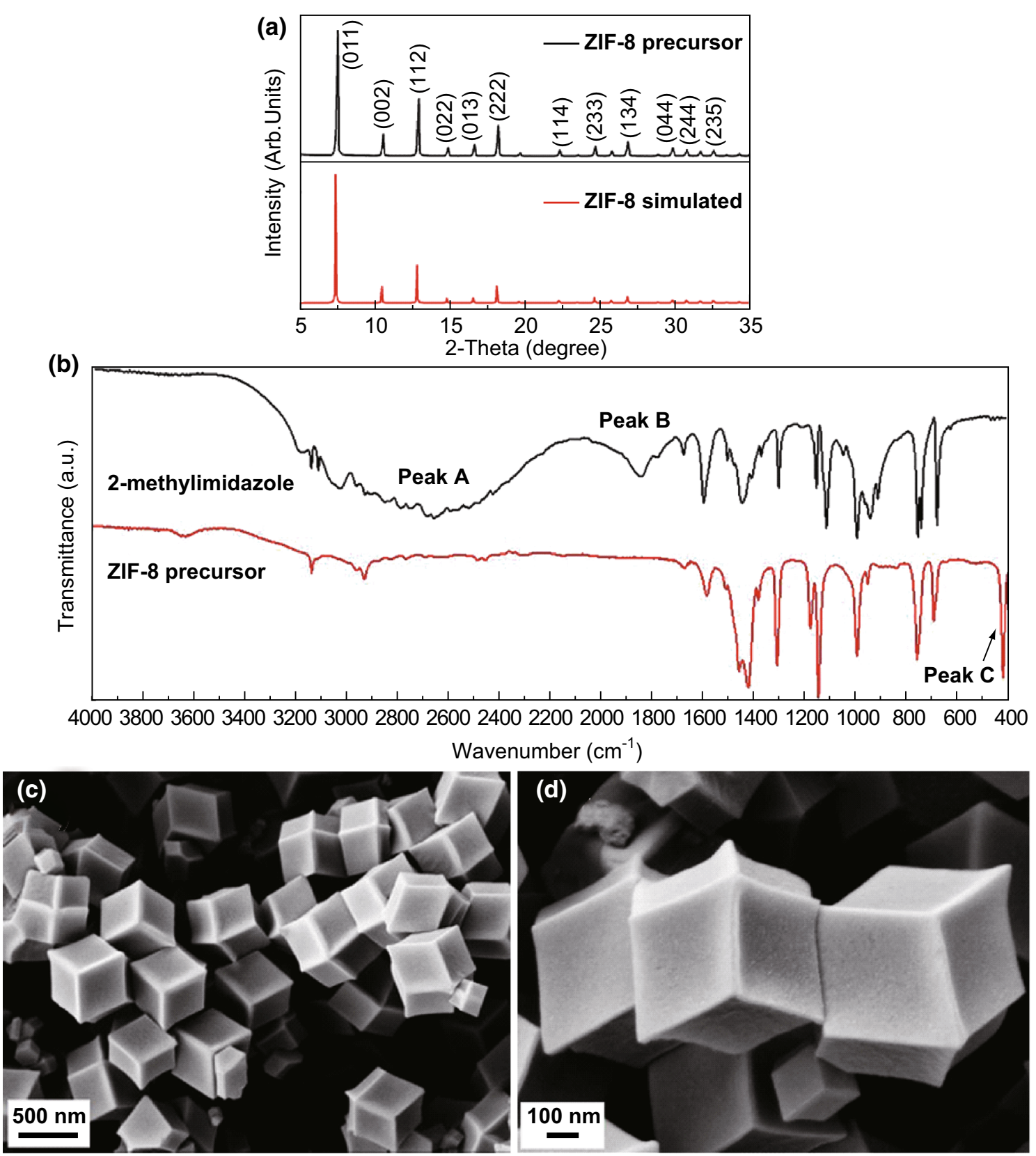

Fig. 3 a XRD pattern, b FTIR spectrum, and c, d SEM images of ZIF-8 precursors

of the ZIF-8 precursor. The intensity of peak at $7.3^{\circ}$ referring to the $\left(\begin{array}{lll}0 & 1 & 1\end{array}\right)$ plane of ZIF-8 is much stronger than other peaks, illustrating an advantageous $\left(\begin{array}{lll}0 & 1 & 1\end{array}\right)$ plane [50]. Figure $3 \mathrm{~b}$ presents the FTIR spectrum of the synthesized ZIF-8 with a comparison of its reactant. The synthesized ZIF-8 exhibits a different FTIR spectrum from MeIm. The wide absorption peak (Peak A) in MeIm caused by vibrations of the hydrogen bonds established between the pyrrole group and the pyridinic nitrogen $(\mathrm{N}-\mathrm{H}$...N) in the range $2200-3200 \mathrm{~cm}^{-1}$ completely disappeared in the synthesized ZIF-8, suggesting that $\mathrm{Zn}^{2+}$ successfully coordinated with MeIm [51]. Obviously, the absorption peak at about $1845 \mathrm{~cm}^{-1}$ (Peak B) in MeIm caused by resonance between the $\mathrm{N}-\mathrm{H}$... $\mathrm{N}$ bending "out of plane", and $\mathrm{N}-\mathrm{H}$ stretching vibrations was not detected in the synthesized ZIF-8 [50, 52]. Meanwhile, a new absorbance peak at about $423 \mathrm{~cm}^{-1}$ (Peak C) appearing in the synthesized $\mathrm{ZIF}-8$ is ascribed to $\mathrm{Zn}-\mathrm{N}$ stretching. These differences further verified the bond connectivity between MeIm and $\mathrm{Zn}^{2+}$, as previously reported in ZIF-8 $[49,53]$. As shown in Fig. 2, due to $\mathrm{Zn} s p^{3}$ hybridization, ZIF-8 exhibited a sodalite zeolite structure formed by four- and six-member ring $\mathrm{ZnN}_{4}$ clusters with large internal vacancies $(1.16 \mathrm{~nm}$ in diameter) $[48,54,55]$. Apparently, the 

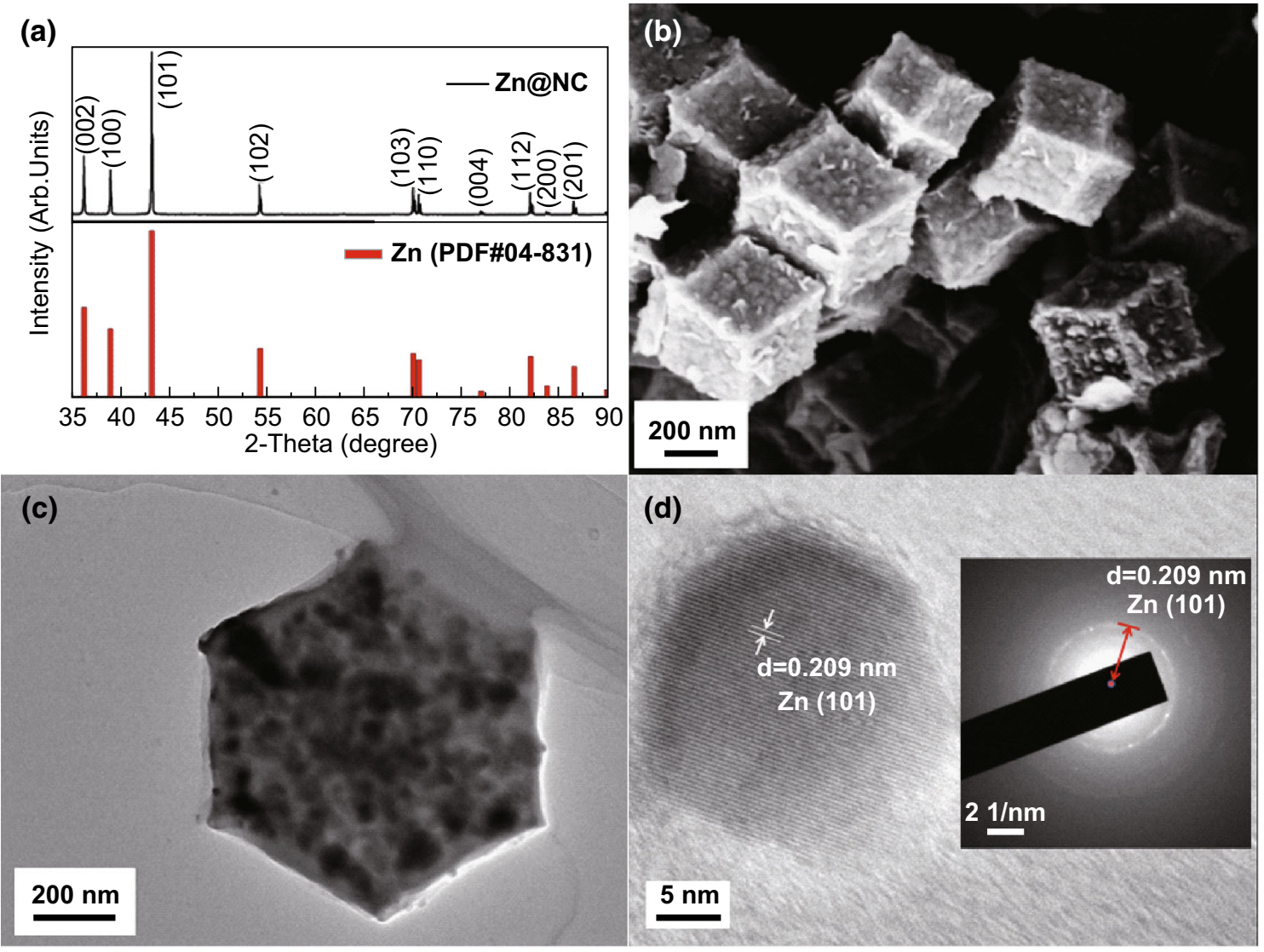

Fig. 4 a XRD pattern, b SEM, c TEM, and d HRTEM and SAED images of Zn@NC

ZIF-8 crystal structure was well formed in the synthesized ZIF-8. Figure $3 c$ presents the SEM image of the synthesized ZIF-8, showing that its particle size is uniform, about $500 \mathrm{~nm}$ with dodecahedral morphology. As depicted in Fig. 3d, the enlarged SEM image of ZIF-8 precursor visually displays its smooth surface, striking angular morphology, and well-defined facets.

As shown in Fig. 2, Zn@NC was obtained by calcining the synthesized ZIF-8. From Fig. S1a to d, the Zn@NC maintains a more complete structure after ZIF-8 calcination at $600{ }^{\circ} \mathrm{C}$, compared to those at 700 and $800{ }^{\circ} \mathrm{C}$. In addition, although the morphology after calcination at $500{ }^{\circ} \mathrm{C}$ was the best in all samples, its degree of graphitization was lower than that of $600{ }^{\circ} \mathrm{C}$ [56]. Therefore, $600{ }^{\circ} \mathrm{C}$ was the optimum temperature for calcination. The resulting Zn@NC was characterized with XRD, SEM, and TEM, and the results obtained are shown clearly in Fig. 4. From the XRD pattern (Fig. 4a), all diffraction peak intensities and positions of Zn@NC matched with those of metallic Zn (PDF\#04-0831). This identification suggested that the organic compositions of ZIF-8 were converted to pyrolytically amorphous carbon composite while the zinc ions in ZIF-8 were reduced by pyrolytic carbon to metallic zinc [57]. From the SEM image (Fig. 4b), it was observed that after the carbonization process, Zn@NC retained the pristine rhombic dodecahedron morphology of ZIF-8 but its surface became rough. The TEM image of Zn@NC (Fig. 4c) reveals that metallic zinc existed in the form of nanoparticles that are distributed in the carbon matrix. The high-resolution TEM (HRTEM) and electron diffraction images (Fig. 4d) indicate that the $\mathrm{Zn}$ nanoparticle was about $15 \mathrm{~nm}$ with $d$-spacing $0.209 \mathrm{~nm}$, which corresponds to the (101) plane of $\mathrm{Zn}$. Raman spectroscopy was carried out to confirm the existence and structure of carbon in Zn@NC. As shown in Fig. S2a, two scattering bands are located at 1328 and $1575 \mathrm{~cm}^{-1}$, which could be defined as the $\mathrm{D}$ and $\mathrm{G}$ bands of carbon, respectively. Moreover, the intensity ratio $I_{\mathrm{D}} / I_{\mathrm{G}}$ was estimated to be about 1.13 , revealing a comparatively low degree of graphitization. This may be due to the generation of gas and re-formation of carbon structure during the carbonization process [58].

$\mathrm{Bi} @ \mathrm{NC}$ was designed by the replacement of zinc by bismuth, as indicated in Fig. 2, which was based on different potentials for bismuth and zinc. The standard hydrogen electrode potential of bismuth, $\mathrm{E}^{\Theta}\left(\mathrm{Bi}^{3+} / \mathrm{Bi}\right)$, is $0.31 \mathrm{~V}$ compared to $-0.7628 \mathrm{~V}$ for zinc, $\mathrm{E}^{\Theta}\left(\mathrm{Zn}^{2+} / \mathrm{Zn}\right)$. The resulting Bi@NC was characterized by XRD, SEM, TEM, EDS, XPS, and BET, which are presented in Figs. 5 

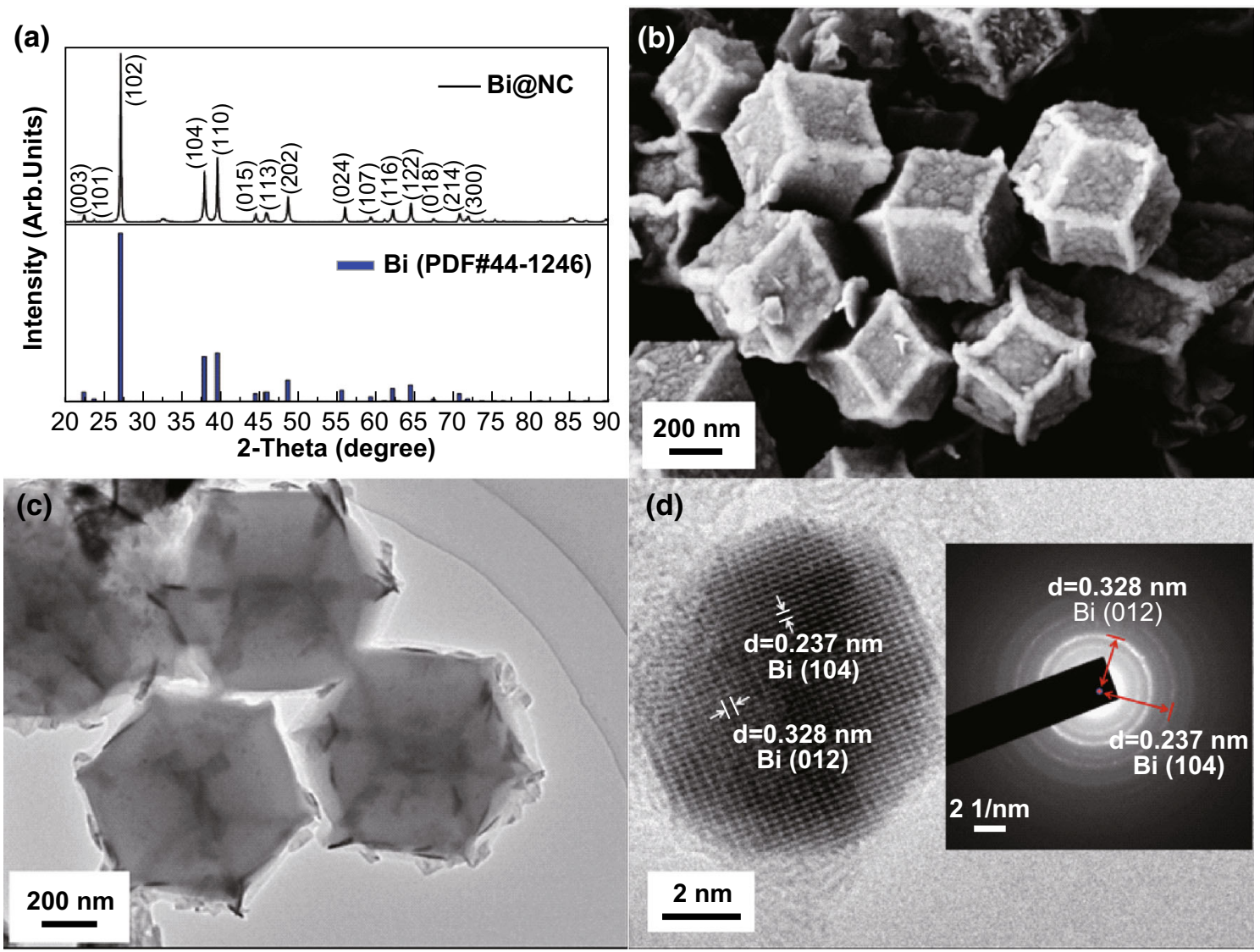

Fig. 5 a XRD pattern, b SEM, c TEM, HRTEM, and d SAED images of Bi@NC

and S3. The XRD pattern (Fig. 5a) illustrates that the diffraction peaks of $\mathrm{Bi} @ \mathrm{NC}$ match those of metallic $\mathrm{Bi}$ (PDF\#44-1246), indicating successful in situ replacement between $\mathrm{Bi}^{3+}$ and $\mathrm{Zn}$. The SEM (Fig. 5b) and TEM images (Fig. 5c) display that the as-prepared Bi@NC retained the rhombic dodecahedral morphology inherited from its precursor and that the $\mathrm{Bi}$ particles are well dispersed in Bi@NC. This configuration provided Bi@NC with an apparent density of $1.51 \mathrm{~g} \mathrm{~cm}^{-3}$, which is nearly twice that of graphite, whose apparent density is about $0.74 \mathrm{~g} \mathrm{~cm}^{-3}$. As shown in Fig. 5d (HRTEM and SAED images), the Bi nanoparticles in Bi@NC had smaller size (about $5 \mathrm{~nm}$ ) than Zn nanoparticles in Zn@NC. This was because the Bi nanoparticles were evenly redistributed in carbon matrices after in situ replacement of $\mathrm{Zn}$ at high pressure during hydrothermal reaction. Meanwhile, lattice spacings of 0.237 and $0.328 \mathrm{~nm}$ are assigned to the (104) and (012) planes of the Bi phase, respectively [59]. EDS detection (Fig. S3a) shows that Bi@NC contained the elements Bi, $\mathrm{C}, \mathrm{N}$, and $\mathrm{O}$ while EDS mapping analysis (Fig. S3b) certifies that $\mathrm{Bi}, \mathrm{C}$, and $\mathrm{N}$ are homogeneously distributed in $\mathrm{Bi} @ \mathrm{NC}$. These analyses indicate that the nitrogen atoms in Zn@NC or Bi@NC are derived from ZIF-8. In addition, as depicted in Fig. S2b, the Raman spectrum of Bi@NC exhibited a lower $I_{\mathrm{D}} / I_{\mathrm{G}}$ ratio $\left(I_{\mathrm{D}} / I_{\mathrm{G}}=1.06\right)$ than $\mathrm{Zn} @ \mathrm{NC}$, suggesting a higher degree of graphitization. The dispersion of $\mathrm{Bi}$ nanoparticles after replacement led to the reduction of defects in carbon during the hydrothermal reaction.

According to previous reports, nitrogen doping in carbon can enhance the electronic conductivity of carbon matrices and create abundant defects (for instance, nanopores) on carbon $[60,61]$. XPS was performed to determine the nitrogen species in Bi@NC. As shown in Fig. S3c, the $\mathrm{N}$ atomic ratio in $\mathrm{Bi} @ \mathrm{NC}$ is about $27.48 \%$, in agreement with EDS analysis. The nitrogen species consisted of pyridinic- $N(\mathrm{~N} 1,398.50 \mathrm{eV})$, pyrrolic- $N(\mathrm{~N} 2,399.70 \mathrm{eV})$, graphitic- $N(\mathrm{~N} 3,400.56 \mathrm{eV})$, and oxidized- $N$ (N4, $401.8 \mathrm{eV}$ ) [62]. Both pyridinic- $N$ and pyrrolic- $N$ in $\mathrm{NC}$ provide more active sites for lithium ion storage, benefiting mass transport and electron transfer [63].

Figure S3d presents $\mathrm{N}_{2}$ adsorption-desorption and corresponding pore diameter distribution curves of $\mathrm{Bi} @ \mathrm{NC}$. The $\mathrm{N}_{2}$ adsorption-desorption isotherm of $\mathrm{Bi} @ \mathrm{NC}$ could be classified as a typical IV $\left(\mathrm{H}_{3}\right)$ isotherm with a distinct hysteresis loop, indicative of the presence of distinct mesoporous microstructures [46]. From the BET result, the specific surface area is $492.08 \mathrm{~m}^{2} \mathrm{~g}^{-1}$ while the single 

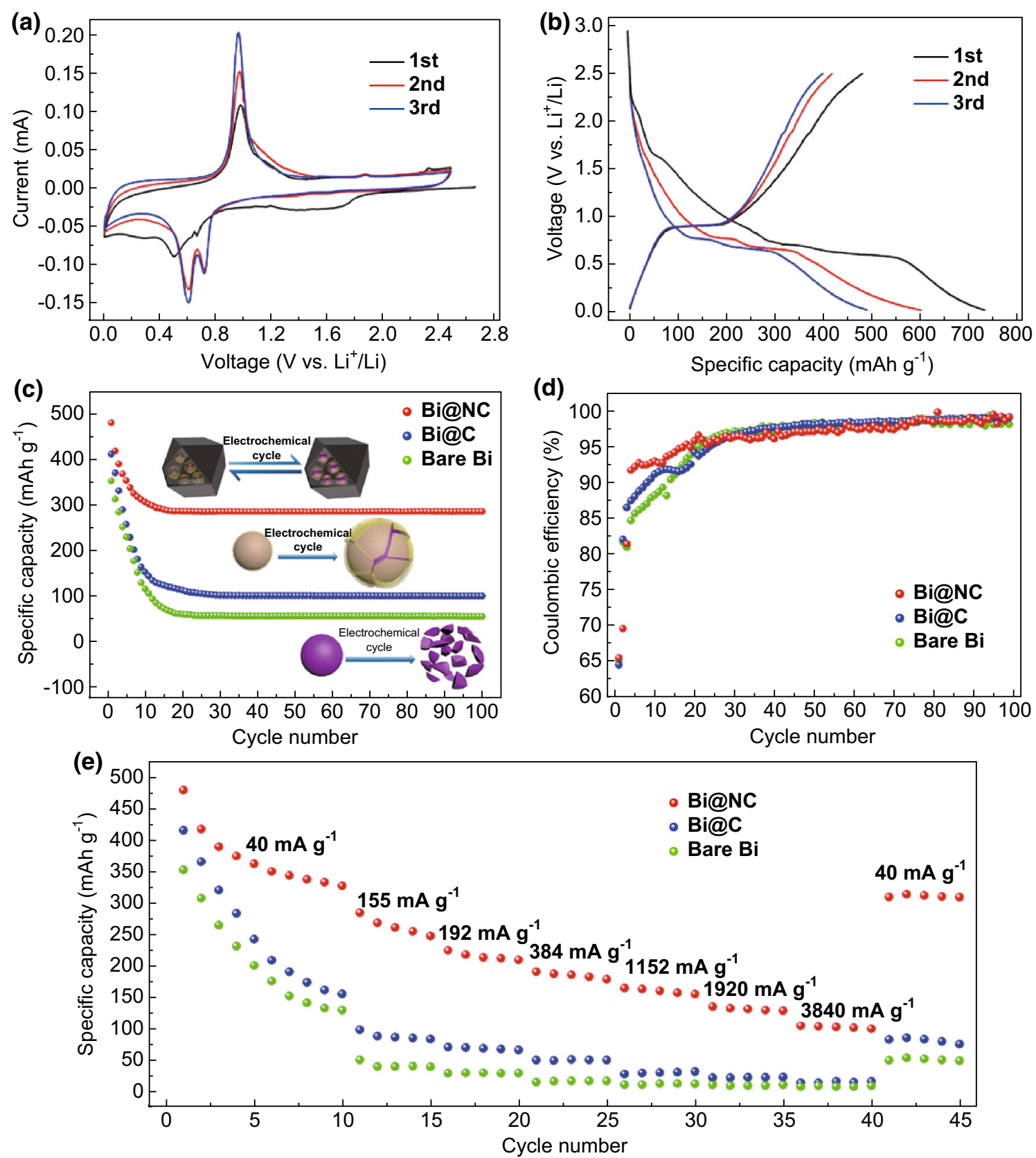

Fig. 6 a Cyclic voltammograms and b charge-discharge curves of Bi@ NC; comparisons of $\mathbf{c}$ cyclic stability, $\mathbf{d}$ coulombic efficiency, and e rate capabilities of Bi@NC, Bi@C, and bare Bi

point adsorption total pore volume is $0.2749 \mathrm{~cm} \mathrm{~g}^{-1}(P /$ $\left.P_{0}=0.9889\right)$. According to the narrow pore size distribution in the range 2.1-5 nm, Bi@NC had an average pore size of about $2.23 \mathrm{~nm}$, which was calculated via desorption data using the Barrett-Joyner-Halenda (BJH) model. Obviously, the as-prepared Bi@NC exhibits a porous structure, which is related to its precursor ZIF-8. This porous structure was helpful for volume buffering during lithium insertion/extraction in bismuth. The nanoparticles of bismuth in $\mathrm{Bi} @ \mathrm{NC}$ reduce the distance for lithium transportation in bismuth while the $\mathrm{NC}$ increases the electronic conductivity and activity of lithium insertion/ extraction. Therefore, the hierarchical configuration of Bi@NC contributes to its excellent electrochemical performances as anode in the lithium ion battery in terms of cyclic stability and rate capability.

The cyclic stability and rate capability of the as-prepared Bi@NC were evaluated in a coin cell with metallic lithium as counter electrode. Figure 6a presents the cyclic voltammograms of $\mathrm{Bi} @ \mathrm{NC}$. Owing to the formation of a solid electrolyte interphase (SEI) layer on the carbon matrix, an irreversible broad peak appeared between 0.01 
and 1.8 $\mathrm{V}$ during the first cathodic scan [46, 64]. The high specific surface area of $\mathrm{Bi} @ \mathrm{NC}$ and reductive decomposition of the electrolyte led to large irreversible capacity loss during the first cycle $[15,65]$. The other two reduction peaks are located at about 0.75 and $0.60 \mathrm{~V}$, which are attributed to the formation of $\mathrm{LiBi}$ and $\mathrm{Li}_{3} \mathrm{Bi}$, respectively $[1,9,66]$. During the anodic process, a sharp peak locates at about $0.9 \mathrm{~V}$ is assigned to the reversible extraction of $\mathrm{Li}^{+}$from $\mathrm{Li}_{3} \mathrm{Bi}$ that returned to metallic $\mathrm{Bi}[18,22,67]$. These reactions were also identified from charge/discharge tests. Figure $6 \mathrm{~b}$ presents the charge-discharge curves of the first three cycles of Bi@NC. There are two voltage plateaus at about 0.75 and $0.6 \mathrm{~V}$ in the discharge curves, corresponding to the formation of $\mathrm{LiBi}$ and $\mathrm{Li}_{3} \mathrm{Bi}$, respectively. The voltage plateaus around $0.9 \mathrm{~V}$ in the charge curves can be ascribed to reversible lithium extraction from $\mathrm{Li}_{3} \mathrm{Bi}$ to Bi. The capacity at a voltage lower than $0.6 \mathrm{~V}$ can be ascribed to capacitive contribution from the porous carbon matrix [46].

Figure 6c presents the cyclic stability of $\mathrm{Bi} @ \mathrm{NC}$ at $80 \mathrm{~mA} \mathrm{~g}^{-1}$ after the initial three cycles at $40 \mathrm{~mA} \mathrm{~g}^{-1}$, with comparisons to bare $\mathrm{Bi}$ and $\mathrm{Bi} @ \mathrm{C}$. A drop-off trend of capacity in the initial cycles was distinctly observed in all samples. This is because $\mathrm{Bi}$ particles pulverized upon cycling, resulting in the loss of electrical integrity leading to rapid capacity fading [1]. Besides, the sizes of Bi particles in bare $\mathrm{Bi}$ and $\mathrm{Bi} @ \mathrm{C}(\mathrm{OD}=100 \mathrm{~nm})$ are larger than that in Bi@NC (OD=5 nm), leading to easier pulverization and faster fading of capacity [21]. The initial first cycle coulombic efficiencies of these three samples (Fig. 6d) are only about $65 \%$, which was ascribed to the formation of SEI on the fresh sample surface during the first cycle. It can be found from Fig. 6c that bare Bi exhibits poor cyclic stability. Its charge capacity decayed quickly before the initial 20 cycles and retained only $60 \mathrm{mAh} \mathrm{g}^{-1}$ after 100 cycles. This poor cyclic stability resulted from pulverization of $\mathrm{Bi}$ nanoparticles due to their volume change during lithium insertion/extraction and electronic insulation of pulverized particles due to surface SEI [1, 17]. The pulverization of $\mathrm{Bi}$ nanoparticles can be clearly indicated by SEM and TEM images of cycled bare $\mathrm{Bi}$, as shown in Fig. S4a. The poor cyclic stability of bare $\mathrm{Bi}$ is improved to some extent by coating carbon on $\mathrm{Bi}$ nanoparticles. As shown in Fig. 6c, the charge capacity of $\mathrm{Bi} @ \mathrm{C}$ is retained at $100 \mathrm{mAh} \mathrm{g}^{-1}$ after 100 cycles. However, this capacity is lower than the theoretical specific capacity of bismuth. Obviously, simple carbon coating did not improve the cyclic stability of bismuth. The large volume change of the bismuth could destroy the carbon-coating layer and expose bismuth to the electrolyte, resulting in pulverization and continuous growth of SEI layers on $\mathrm{Bi}$ particle surfaces [68]. The TEM and SEM images in Fig. S4b confirm the destruction of $\mathrm{Bi} @ \mathrm{C}$ particles. $\mathrm{Bi} @ \mathrm{NC}$, in contrast, showed excellent cyclic stability, with charge capacity (285 $\mathrm{mAh} \mathrm{g}^{-1}$ ) that is higher than those of bare $\mathrm{Bi}$ or Bi@C.Bi@NC showed excellent cyclic stability with charge capacity $\left(285 \mathrm{mAh}^{-1}\right)$ that is significantly higher than those of bare Bi or Bi@C. The electrochemical performances of $\mathrm{Bi} @ \mathrm{NC}$ were compared with previous reports in the literature, as displayed in Table S1. The corresponding volumetric capacity is about $430 \mathrm{mAh} \mathrm{cm}^{-3}$ (specific capacity $\times$ apparent density $=285 \mathrm{mAh} \mathrm{g}^{-1-}$ $\times 1.51 \mathrm{~g} \mathrm{~cm}^{-3}$ ) at current density $80 \mathrm{~mA} \mathrm{~g}^{-1}$, which is also 1.5 times that of graphite $\left(275 \mathrm{mAh} \mathrm{cm}^{-3}\right.$, specific capacity $\times$ apparent density $=372 \mathrm{mAh} \mathrm{g}^{-1-}$ $\times 0.74 \mathrm{~g} \mathrm{~cm}^{-3}$ ). This excellent performance is attributed to the porous structure of the carbon matrix, which provides space to alleviate the mechanical strain of $\mathrm{Bi}$ nanoparticles during lithium insertion/extraction and maintains the structural integrity of Bi (Fig.S5b) [46]. The NC matrix is just like a huge conductive network where the smaller and higher active Bi nanoparticles are anchored, resulting in preferable electrochemical performance compared to bare Bi and Bi@C. Even after 100 cycles, Bi@ NC maintains its pristine morphology, as indicated by the TEM and SEM of cycled Bi@NC (Fig. S4c).

Bi@NC exhibited excellent rate capability. Figure 6e presents the rate capability of Bi@NC compared to bare Bi and Bi@C. Obviously, bare Bi and Bi@C almost lost their charge capacities, but Bi@NC delivered a capacity as high as $100 \mathrm{mAh} \mathrm{g}^{-1}$ under a high rate current of $3840 \mathrm{~mA} \mathrm{~g}^{-1}$. This excellent rate capability is related to the smaller bismuth nanoparticles uniformly anchored in the NC than those in bare Bi and Bi@C. The smaller nanoparticles shortened the path for lithium transport in the particles and the nitrogen-doped carbon enhanced the electronic conductivity of $\mathrm{Bi}$. It should be noted from Fig. 6c that at low rate current, Bi@ NC delivered a charge capacity (over $400 \mathrm{mAh} \mathrm{g}^{-1}$ ) higher than the theoretical specific capacities of bismuth and carbon. This could be ascribed to the capacitive contribution of the high specific surface of the carbon matrix in $\mathrm{Bi} @ \mathrm{NC}$.

To understand the electrochemical behavior of $\mathrm{NC}$ during cycling, its cycle and rate performance were investigated, as shown in Fig. S6a, b. According to previous literature, we propose that $\mathrm{Li}$ ions were stored in $\mathrm{NC}$ because the $\mathrm{Li}$ ions had strong interactions with $\mathrm{N}$ atoms [69, 70]. Figure S6a presents the cyclic stability of NC at $80 \mathrm{~mA} \mathrm{~g}^{-1}$ after the initial three cycles at $40 \mathrm{~mA} \mathrm{~g}^{-1}$. The first cycle coulombic efficiency of NC is also low, about $58 \%$. The low coulombic efficiency is attributed to the formation of SEI and storage of $\mathrm{Li}$ ions in nanoporous voids, which are difficult to extract [71]. As the cycling at $80 \mathrm{~mA} \mathrm{~g}^{-1}$ proceeded further, the capacity of NC quickly stabilized to exhibited good electrochemical performance with high reversible capacity of about $215 \mathrm{mAh} \mathrm{g}^{-1}$ up to 

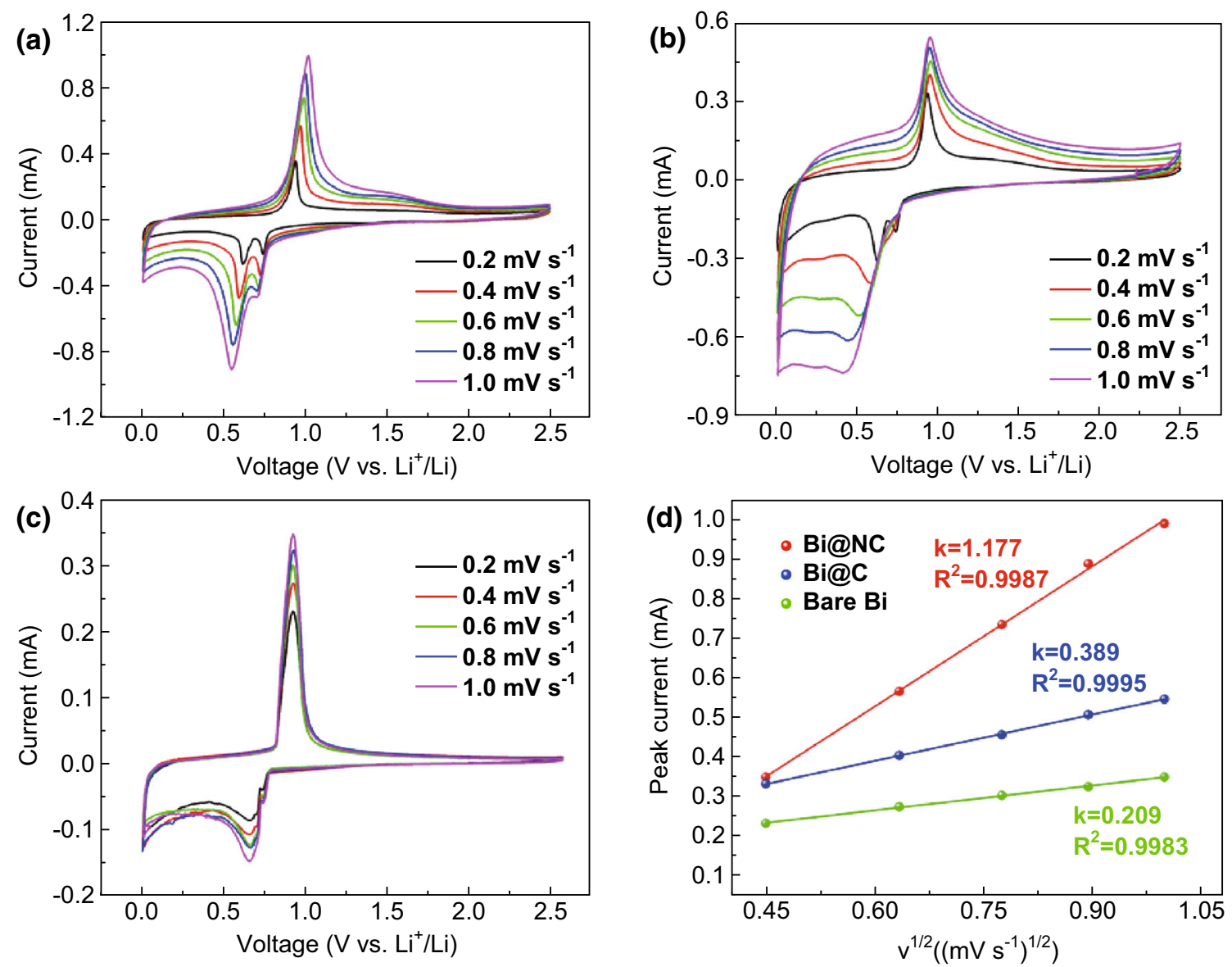

Fig. $7 \mathrm{CV}$ characteristics of a Bi@NC, b Bi@C and $\mathbf{c}$ bare Biat scanning rates ranging from 0.2 to $1.0 \mathrm{mV} \mathrm{s}^{-1}$. $\mathbf{d}$ Linear relations of anodic peak currents $\left(i_{\mathrm{p}}\right)$ versus the square roots of scanning rate $(v)$

100 charge/discharge cycles. The rate performance of NC was evaluated at various current densities from 80 to $3840 \mathrm{~mA} \mathrm{~g}^{-1}$, as shown in Fig. S6b. As can be seen, the reversible capacities remain stable and decreased regularly with increase in rate. Therefore, there is reason to believe that $\mathrm{NC}$ is an excellent carbon matrix that could improve the electrochemical performance of Bi particles in Bi@NC relative to bare $\mathrm{Bi}$ or its simple composite with carbon.

To further understand the kinetic processes of Bi@NC, $\mathrm{Bi} @ \mathrm{C}$, and bare Bi during lithium insertion/extraction, the lithium ion diffusion coefficient $(D)$ was expected. CV characteristics of Bi@NC, Bi@C, and bare Bi at different scanning rates were measured after activation, as shown in Fig. $7 \mathrm{a}-\mathrm{c}$. The linear relationship between anodic peak current $\left(i_{\mathrm{p}}\right)$ and square root of scanning rate $(v)$ is seen in Fig. $7 \mathrm{~d}$. The $D$ is extracted by the Randles-Sevcik equation [72]:

$i_{\mathrm{p}}=2.69 \times 10^{5} n^{3 / 2} A D^{1 / 2} C v^{1 / 2}$ where $i_{\mathrm{p}}$ refers to the peak current, $n$ is the number of electrons in the reaction, $A$ is the electrode area, $C$ is the concentration of lithium ion in the electrolyte, and $v$ is the scanning rate. The slopes of the fitted lines in Fig. $7 \mathrm{~d}$ represent the lithium diffusion coefficients. The $D$ for $\mathrm{Bi} @ \mathrm{NC}$ cycling from 0.01 to $2.5 \mathrm{~V}$ was $7.45 \times 10^{-7} \mathrm{~cm}^{2} \mathrm{~s}^{-1}$, which is about 3.0 and 5.5 times larger than those of $\mathrm{Bi} @ \mathrm{C}\left(2.46 \times 10^{-7} \mathrm{~cm}^{2} \mathrm{~s}^{-1}\right)$ and bare Bi $\left(1.32 \times 10^{-7} \mathrm{~cm}^{2} \mathrm{~s}^{-1}\right)$. These results indicate faster insertion and extraction rate of lithium ions in $\mathrm{Bi} @ \mathrm{NC}$ than in $\mathrm{Bi} @ \mathrm{C}$ and bare $\mathrm{Bi}$, and match the excellent rate performance of $\mathrm{Bi} @ \mathrm{NC}$. It also proved that NC could increase the insertion and extraction rates of lithium ions in Bi due to the former's porous structure and nitrogen-doping $[64,73]$.

The electrochemical impedance test was also measured to examine the kinetic process. In Fig. S7a-c, the electrochemical impendence spectra of $\mathrm{Bi} @ \mathrm{NC}$, bare $\mathrm{Bi}$, and Bi@C half-cells are presented. The semicircle's diameter stands for charge-transfer resistance. Although the Bi@NC 

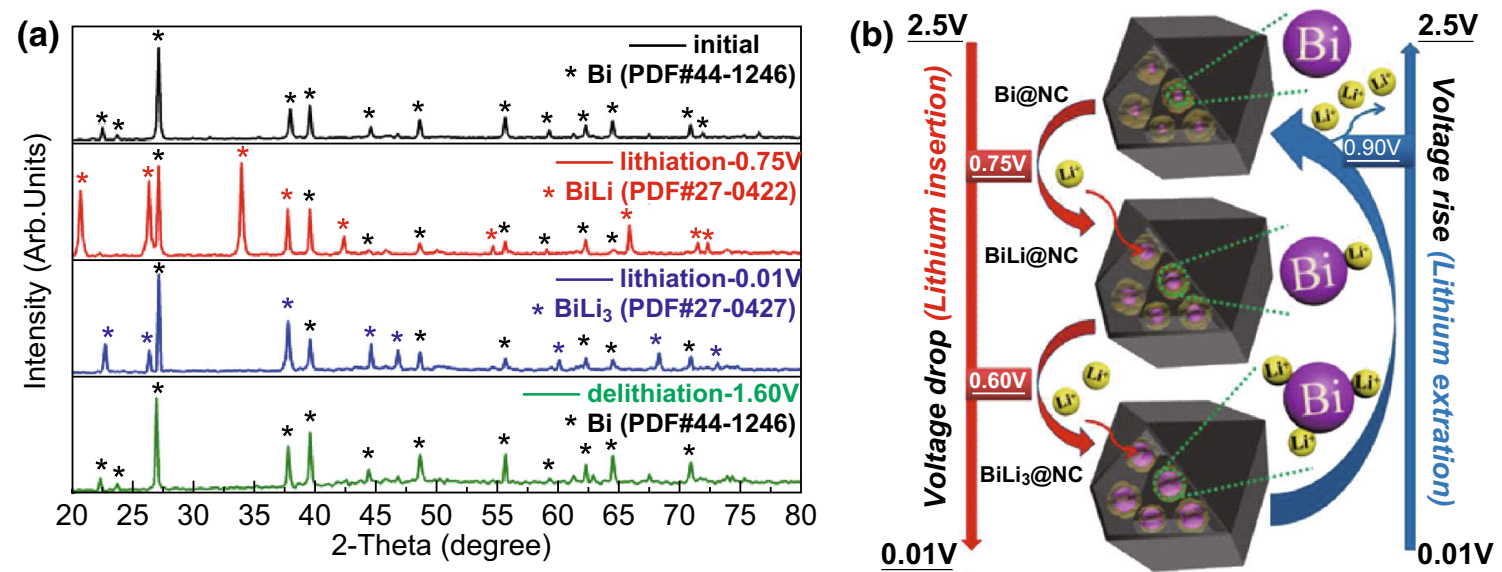

Fig. 8 XRD patterns revealing a structural and chemical evolution and $\mathbf{b}$ corresponding mechanism of the Bi@NC electrode

half-cells had larger internal resistance than the other two in the initial stage, its rate of increase in resistance is slower, which can be clearly observed in Fig. S7d. This is attributed to the differences in the structures of $\mathrm{Bi} @ \mathrm{NC}$, bare $\mathrm{Bi}$, and $\mathrm{Bi} @ \mathrm{C}$. In $\mathrm{Bi} @ \mathrm{NC}$, the Bi nanoparticles are uniformly dispersed in the carbon matrix and most maintain their structural integrities with few SEI layers on the surface after cycling (Fig. S5a, b). In bare Bi and Bi@C, the pulverization of $\mathrm{Bi}$ nanoparticles and continuous growth of SEI layers on Bi particle surfaces result in fast growth of resistance.

The structural and compositional integrity of Bi@NC was confirmed by identifying its XRD patterns during lithium insertion/extraction. As shown in Fig. 8a, which was obtained during the first charge/discharge process, some $\mathrm{Bi}$ is transformed to an $\mathrm{LiBi}$ phase when the voltage decreased from 2 to $0.75 \mathrm{~V}$. $\mathrm{Li}_{3} \mathrm{Bi}$ was formed when the voltage was $0.60 \mathrm{~V}$. These reactions were reversible. With these reversible reactions, shown in Fig. 8b, Bi@NC exhibited excellent cyclic stability.

\section{Conclusions}

A novel bismuth-carbon composite, in which bismuth nanoparticles were anchored in nitrogen-doped porous carbon matrices (Bi@NC), was successfully fabricated by galvanic replacement reaction in an MOF (ZIF-8). In this composite, the carbon matrices maintain the morphology of ZIF-8 and exhibit a porous structure, providing space to alleviate the mechanical strain of Bi nanoparticles during $\mathrm{Li}$ insertion/extraction. Nitrogen-doped carbon increased the electronic conductivity of the matrix and the reaction activity of bismuth for lithium insertion/extraction. Bismuth nanoparticles uniformly distributed in the carbon matrix reduced the path for lithium transport in the particles. With these features, the as-prepared Bi@NC exhibits excellent cyclic stability and rate capability. The strategy developed in this work solves the cyclic instability issue of bismuth as anode for the lithium ion battery and provides a new approach to high volumetric energy density for electrochemical energy storage devices.

Acknowledgements This work is supported by the Natural Science Foundation of Guangdong Province (Grant No. 2017B030306013) and the key project of Science and Technology in Guangdong Province (Grant No. 2017A010106006).

Open Access This article is distributed under the terms of the Creative Commons Attribution 4.0 International License (http://crea tivecommons.org/licenses/by/4.0/), which permits unrestricted use, distribution, and reproduction in any medium, provided you give appropriate credit to the original author(s) and the source, provide a link to the Creative Commons license, and indicate if changes were made.

\section{References}

1. C.F. Sun, J.K. Hu, P. Wang, X.Y. Cheng, S.B. Lee, Y.H. Wang, $\mathrm{Li}_{3} \mathrm{PO}_{4}$ matrix enables a long cycle life and high energy efficiency bismuth-based battery. Nano Lett. 16(9), 5875-5882 (2016). https://doi.org/10.1021/acs.nanolett.6b02720

2. P. Xia, H.B. Lin, W.Q. Tu, X.Q. Chen, X. Cai, X.W. Zheng, M.Q. $\mathrm{Xu}$, W.S. Li, A novel fabrication for manganese monoxide/reduced graphene oxide nanocomposite as high performance anode of lithium ion battery. Electrochim. Acta 198, 66-76 (2016). https://doi.org/10.1016/j.electacta.2016.03.077

3. H.B. Lin, J.N. Hu, H.B. Rong, Y.M. Zhang, S.W. Mai, L.D. Xing, M.Q. Xu, X.P. Li, W.S. Li, Porous $\mathrm{LiMn}_{2} \mathrm{O}_{4}$ cubes architectured with single-crystalline nanoparticles and exhibiting excellent cyclic stability and rate capability as the cathode of a lithium ion battery. J. Mater. Chem. A 2(24), 9272-9279 (2014). https://doi. org/10.1039/c4ta01474j

4. H.B. Lin, Y.M. Zhang, H.B. Rong, S.W. Mai, J.N. Hu et al., Crystallographic facet- and size-controllable synthesis of spinel $\mathrm{LiNi}_{0.5} \mathrm{Mn}_{1.5} \mathrm{O}_{4}$ with excellent cyclic stability as cathode of high voltage lithium ion battery. J. Mater. Chem. A 2(30), 11987-11995 (2014). https://doi.org/10.1039/c4ta01810a 
5. H.B. Lin, H.B. Rong, W.Z. Huang, Y.H. Liao, L.D. Xing, M.Q. $\mathrm{Xu}$, X.P. Li, W.S. Li, Triple-shelled $\mathrm{Mn}_{2} \mathrm{O}_{3}$ hollow nanocubes: force-induced synthesis and excellent performance as the anode in lithium-ion batteries. J. Mater. Chem. A 2(34), 14189-14194 (2014). https://doi.org/10.1039/c4ta02666g

6. X. Dong, N. Hu, L. Wei, Y. Su, H. Wei, L. Yao, X. Li, Y. Zhang, A new strategy to prepare N-doped holey graphene for highvolumetric supercapacitors. J. Mater. Chem. A 4(25), 9739-9743 (2016). https://doi.org/10.1039/C6TA01406B

7. B. Li, X.P. Li, W.S. Li, Y.Q. Wang, E. Uchaker et al., Mesoporous tungsten trioxide polyaniline nanocomposite as an anode material for high-performance lithium-ion batteries. ChemNanoMat 2(4), 281-289 (2016). https://doi.org/10.1002/cnma. 201500208

8. X.Q. Chen, Y.M. Zhu, B. Li, P.B. Hong, X.Y. Luo, X.X. Zhong, L.D. Xing, W.S. Li, Porous manganese oxide nanocubes enforced by solid electrolyte interphase as anode of high energy density battery. Electrochim. Acta 224, 251-259 (2017). https://doi.org/ 10.1016/j.electacta.2016.12.079

9. W. Fang, N.Q. Zhang, L.S. Fan, K.N. Sun, $\mathrm{Bi}_{2} \mathrm{O}_{3}$ nanoparticles encapsulated by three-dimensional porous nitrogen-doped graphene for high-rate lithium ion batteries. J. Power Sources 333, 30-36 (2016). https://doi.org/10.1016/j.jpowsour.2016.09.155

10. X.Q. Chen, H.B. Lin, X.W. Zheng, X. Cai, P. Xia, Y.M. Zhu, X.P. Li, W.S. Li, Fabrication of core-shell porous nanocubic $\mathrm{Mn}_{2} \mathrm{O}_{3} @ \mathrm{TiO}_{2}$ as a high-performance anode for lithium ion batteries. J. Mater. Chem. A 3(35), 18198-18206 (2015). https://doi. org/10.1039/c5ta04238k

11. Y.Q. Chen, J.T. Li, G.H. Yue, X.Y. Luo, Novel Ag@nitrogendoped porous carbon composite with high electrochemical performance as anode materials for lithium-ion batteries. Nano-Micro Lett. 9(3), 32 (2017). https://doi.org/10.1007/s40820-0170131-y

12. C.-H. Yim, E.A. Baranova, F.M. Courtel, Y. Abu-Lebdeh, I.J. Davidson, Synthesis and characterization of macroporous tin oxide composite as an anode material for $\mathrm{Li}$-ion batteries. J. Power Sources 196(22), 9731-9736 (2011). https://doi.org/10. 1016/j.jpowsour.2011.07.061

13. X.W. Li, Z.B. Yang, Y.J. Fu, L. Qiao, H.W. Yue, D.Y. He, Germanium anode with excellent lithium storage performance in a germanium/lithium-cobalt oxide lithium-ion battery. ACS Nano 9(2), 1858-1867 (2015). https://doi.org/10.1021/ nn506760p

14. D.W. Su, S.X. Dou, G.X. Wang, Bismuth: a new anode for the Na-ion battery. Nano Energy 12, 88-95 (2015). https://doi.org/10. 1016/j.nanoen.2014.12.012

15. R. Dai, Y.H. Wang, P.M. Da, H. Wu, M. Xu, G.F. Zheng, Indirect growth of mesoporous $\mathrm{Bi} @ \mathrm{C}$ core-shell nanowires for enhanced lithium-ion storage. Nanoscale 6(21), 13236-13241 (2014). https://doi.org/10.1039/c4nr04378b

16. G. Keskar, E. Iyyamperumal, D.A. Hitchcock, J. He, A.M. Rao, L.D. Pfefferle, Significant improvement of thermoelectric performance in nanostructured bismuth networks. Nano Energy 1(5), 706-713 (2012). https://doi.org/10.1016/j.nanoen.2012.06.005

17. J.F. Ni, X.X. Bi, Y. Jiang, L. Li, J. Lu, Bismuth chalcogenide compounds $\mathrm{Bi}_{2} \mathrm{X}_{3}(\mathrm{X}=\mathrm{O}, \mathrm{S}, \mathrm{Se})$ : applications in electrochemical energy storage. Nano Energy 34, 356-366 (2017). https://doi.org/ 10.1016/j.nanoen.2017.02.041

18. H. Liang, J. Ni, L. Li, Bio-inspired engineering of $\mathrm{Bi}_{2} \mathrm{~S}_{3}-\mathrm{PPY}$ yolk-shell composite for highly durable lithium and sodium storage. Nano Energy 33, 213-220 (2017). https://doi.org/10. 1016/j.nanoen.2017.01.033

19. A. Finke, P. Poizot, C. Guéry, L. Dupont, P.-L. Taberna, P. Simon, J.-M. Tarascon, Electrochemical method for direct deposition of nanometric bismuth and its electrochemical properties vs Li. Electrochem. Solid-State Lett. 11(3), E5-E9 (2008). https://doi.org/10.1149/1.2826705

20. Y.Y. Shao, M. Gu, X.L. Li, Z.M. Nie, P.J. Zuo et al., Highly reversible $\mathrm{Mg}$ insertion in nanostructured $\mathrm{Bi}$ for $\mathrm{Mg}$ ion batteries. Nano Lett. 14(1), 255-260 (2014). https://doi.org/10.1021/ nl403874y

21. C.-M. Park, S. Yoon, S.-I. Lee, H.-J. Sohn, Enhanced electrochemical properties of nanostructured bismuth-based composites for rechargeable lithium batteries. J. Power Sources 186(1), 206-210 (2009). https://doi.org/10.1016/j.jpowsour.2008.09.097

22. F.H. Yang, F. Yu, Z.A. Zhang, K. Zhang, Y.Q. Lai, J. Li, Bismuth nanoparticles embedded in carbon spheres as anode materials for sodium/lithium-ion batteries. Chem. Eur. J. 22(7), 2333-2338 (2016). https://doi.org/10.1002/chem.201503272

23. B.Z. Li, Y. Wang, L. Xue, X.P. Li, W.S. Li, Acetylene blackembedded $\mathrm{LiMn}_{0.8} \mathrm{Fe}_{0.2} \mathrm{PO}_{4} / \mathrm{C}$ composite as cathode for lithium ion battery. J. Power Sources 232, 12-16 (2013). https://doi.org/ 10.1016/j.jpowsour.2013.01.019

24. Y. Zhao, D.L. Gao, J.F. Ni, L.J. Gao, J. Yang, Y. Li, One-pot facile fabrication of carbon-coated $\mathrm{Bi}_{2} \mathrm{~S}_{3}$ nanomeshes with efficient Li-storage capability. Nano Res. 7(5), 765-773 (2014). https://doi.org/10.1007/s12274-014-0437-8

25. D.C. Lin, Y.Y. Liu, Y. Cui, Reviving the lithium metal anode for high-energy batteries. Nat. Nanotechnol. 12(3), 194-206 (2017). https://doi.org/10.1038/nnano.2017.16

26. J. Tang, S.C. Wu, T. Wang, H. Gong, H.B. Zhang, S.M. Alshehri, T. Ahamad, H.S. Zhou, Y. Yamauchi, Cage-type highly graphitic porous carbon- $\mathrm{Co}_{3} \mathrm{O}_{4}$ polyhedron as the cathode of lithiumoxygen batteries. ACS Appl. Mater. Interfaces 8(4), 2796-2804 (2016). https://doi.org/10.1021/acsami.5b11252

27. C. Kim, K.S. Yang, M. Kojima, K. Yoshida, Y.J. Kim, Y.A. Kim, M. Endo, Fabrication of electrospinning-derived carbon nanofiber webs for the anode material of lithium-ion secondary batteries. Adv. Funct. Mater. 16(18), 2393-2397 (2006). https://doi.org/10. 1002/adfm.200500911

28. Y. Yu, L. Gu, C. Wang, A. Dhanabalan, P.A. Vanaken, J. Maier, Encapsulation of Sn@carbon nanoparticles in bamboo-like hollow carbon nanofibers as an anode material in lithium-based batteries. Angew. Chem. Int. Edit. 48(35), 6485-6489 (2009). https://doi.org/10.1002/anie.200901723

29. J. Liang, X.Y. Yu, H. Zhou, H.B. Wu, S. Ding, X.W. Lou, Bowllike $\mathrm{SnO}_{2} @$ @arbon hollow particles as an advanced anode material for lithium-ion batteries. Angew. Chem. Int. Edit. 53(47), 12803-12807 (2014). https://doi.org/10.1002/anie. 201407917

30. H.Y. Yue, Q.X. Wang, Z.P. Shi, C. Ma, Y.M. Ding, N.N. Huo, J. Zhang, S.T. Yang, Porous hierarchical nitrogen-doped carbon coated $\mathrm{ZnFe}_{2} \mathrm{O}_{4}$ composites as high performance anode materials for lithium ion batteries. Electrochim. Acta 180, 622-628 (2015). https://doi.org/10.1016/j.electacta.2015.08.139

31. Y.Z. Han, P.F. Qi, X. Feng, S.W. Li, X.T. Fu et al., In situ growth of MOFs on the surface of Si nanoparticles for highly efficient lithium storage: Si@MOF nanocomposites as anode materials for lithium-ion batteries. ACS Appl. Mater. Interfaces 7(4), 2178-2182 (2015). https://doi.org/10.1021/am5081937

32. Z.X. Sun, C. Cao, W.-Q. Han, A scalable formation of nano-SnO anode derived from Tin metal-organic frameworks for lithiumion battery. RSC Adv. 5(89), 72825-72829 (2015). https://doi. org/10.1039/c5ra12295c

33. G. Huang, F.F. Zhang, X.C. Du, Y.L. Qin, D.M. Yin, L.M. Wang, Metal organic frameworks route to in situ insertion of multiwalled carbon nanotubes in $\mathrm{Co}_{3} \mathrm{O}_{4}$ polyhedra as anode materials for lithium-ion batteries. ACS Nano 9(2), 1592-1599 (2015). https://doi.org/10.1021/nn506252u

34. A. Mahmood, W. Guo, H. Tabassum, R. Zou, Metal-organic framework-based nanomaterials for electrocatalysis. Adv. Energy 
Mater. 6(17), 1600423 (2016). https://doi.org/10.1002/aenm. 201600423

35. H. Hu, B.Y. Guan, X.W. Lou, Construction of complex CoS hollow structures with enhanced electrochemical properties for hybrid supercapacitors. Chem 1(1), 102-113 (2016). https://doi. org/10.1016/j.chempr.2016.06.001

36. D.W. Wang, Z.W. Li, J. Zhou, H. Fang, X. He, P. Jena, J.-B. Zeng, W.-N. Wang, Simultaneous detection and removal of formaldehyde at room temperature: Janus Au@ZnO@ZIF-8 nanoparticles. Nano-Micro Lett. 10(1), 4 (2017). https://doi.org/ 10.1007/s40820-017-0158-0

37. X.L. Xu, H. Wang, J.B. Liu, H. Yan, The applications of zeolitic imidazolate framework- 8 in electrical energy storage devices: a review. J. Mater. Sci.-Mater. Electron. 28(11), 7532-7543 (2017). https://doi.org/10.1007/s10854-017-6485-6

38. S.L. Zhang, B.Y. Guan, H.B. Wu, X.W. Lou, Metal-organic framework-assisted synthesis of compact $\mathrm{Fe}_{2} \mathrm{O}_{3}$ nanotubes in $\mathrm{Co}_{3} \mathrm{O}_{4}$ host with enhanced lithium storage properties. Nano-Micro Lett. 10(3), 44 (2018). https://doi.org/10.1007/s40820-0180197-1

39. S.G. Wang, J.W. Qin, T. Meng, M.H. Cao, Metal-organic framework-induced construction of actiniae-like carbon nanotube assembly as advanced multifunctional electrocatalysts for overall water splitting and Zn-air batteries. Nano Energy 39, 626-638 (2017). https://doi.org/10.1016/j.nanoen.2017.07.043

40. J.J. Liang, C.C. Yuan, H.H. Li, K. Fan, Z.X. Wei, H.Q. Sun, J.M. $\mathrm{Ma}$, Growth of $\mathrm{SnO}_{2}$ nanoflowers on N-doped carbon nanofibers as anode for Li- and Na-ion batteries. Nano-Micro Lett. 10(2), 21 (2017). https://doi.org/10.1007/s40820-017-0172-2

41. Y.H. Song, L. Zuo, S.H. Chen, J.F. Wu, H.Q. Hou, L. Wang, Porous nano-Si/carbon derived from zeolitic imidazolate frameworks@nano-Si as anode materials for lithium-ion batteries. Electrochim. Acta 173, 588-594 (2015). https://doi.org/10.1016/ j.electacta.2015.05.111

42. H.B. Zhang, J.W. Nai, L. Yu, X.W. Lou, Metal-organic-framework-based materials as platforms for renewable energy and environmental applications. Joule 1(1), 77-107 (2017). https:// doi.org/10.1016/j.joule.2017.08.008

43. J.T. Zhang, L. Yu, X.W. Lou, Embedding $\mathrm{CoS}_{2}$ nanoparticles in $\mathrm{N}$-doped carbon nanotube hollow frameworks for enhanced lithium storage properties. Nano Res. 10(12), 4298-4304 (2017). https://doi.org/10.1007/s12274-016-1394-1

44. Y.Z. Han, P.F. Qi, J.W. Zhou, X. Feng, S.W. Li, X.T. Fu, J.S. Zhao, D.N. Yu, B. Wang, Metal-organic frameworks (Mofs) as sandwich coating cushion for silicon anode in lithium ion batteries. ACS Appl. Mater. Interfaces 7(48), 26608-26613 (2015). https://doi.org/10.1021/acsami.5b08109

45. C.P. Su, Z. Lu, H.P. Zhao, H. Yang, R. Chen, Photoinduced switchable wettability of bismuth coating with hierarchical dendritic structure between superhydrophobicity and superhydrophilicity. Appl. Surf. Sci. 353, 735-743 (2015). https://doi. org/10.1016/j.apsusc.2015.06.180

46. Z. Yi, Q.G. Han, P. Zan, Y.M. Wu, Y. Cheng, L.M. Wang, Sb nanoparticles encapsulated into porous carbon matrixes for highperformance lithium-ion battery anodes. J. Power Sources 331, 16-21 (2016). https://doi.org/10.1016/j.jpowsour.2016.09.027

47. S.R. Venn, J.B. Jasinski, M.A. Carreon, Structural evolution of zeolitic imidazolate framework-8. J. Am. Chem. Soc. 132(51), 18030-18033 (2010). https://doi.org/10.1021/ja109268m

48. H.T. Kwon, H.K. Jeong, In situ synthesis of thin zeolitic-imidazolate framework ZIF-8 membranes exhibiting exceptionally high propylene/propane separation. J. Am. Chem. Soc. 135(29), 10763-10768 (2013). https://doi.org/10.1021/ja403849c

49. J.B. James, Y.S. Lin, Kinetics of zif-8 thermal decomposition in inert, oxidizing, and reducing environments. J. Phys. Chem. C
120(26), 14015-14026 (2016). https://doi.org/10.1021/acs.jpcc. 6b01208

50. X.Y. Li, X.Y. Gao, L.H. Ai, J. Jiang, Mechanistic insight into the interaction and adsorption of $\mathrm{Cr}$ (VI) with zeolitic imidazolate framework-67 microcrystals from aqueous solution. Chem. Eng. J. 274, 238-246 (2015). https://doi.org/10.1016/j.cej.2015.03.127

51. E.L. Bustamante, J.L. Fernandez, J.M. Zamaro, Influence of the solvent in the synthesis of zeolitic imidazolate framework-8 (ZIF8) nanocrystals at room temperature. J. Colloid Interface Sci. 424, 37-43 (2014). https://doi.org/10.1016/j.jcis.2014.03.014

52. Z. Li, X.X. Huang, C.L. Sun, X.Y. Chen, J.B. Hu, A. Stein, B. Tang, Thin-film electrode based on zeolitic imidazolate frameworks (ZIF-8 and ZIF-67) with ultra-stable performance as a lithium-ion battery anode. J. Mater. Sci. 52(7), 3979-3991 (2016). https://doi.org/10.1007/s10853-016-0660-7

53. Y. Hu, H. Kazemian, S. Rohani, Y.N. Huang, Y. Song, In situ high pressure study of Zif- 8 by ftir spectroscopy. Chem. Commun. 47(47), 12694-12696 (2011). https://doi.org/10.1039/ $\mathrm{c} 1 \mathrm{cc} 15525 \mathrm{c}$

54. J. Im, N. Yim, J. Kim, T. Vogt, Y. Lee, High-pressure chemistry of a zeolitic imidazolate framework compound in the presence of different fluids. J. Am. Chem. Soc. 138(36), 11477-11480 (2016). https://doi.org/10.1021/jacs.6b07374

55. H.-Y. Cho, J. Kim, S.-N. Kim, W.-S. Ahn, High yield 1-1 scale synthesis of zif-8 via a sonochemical route. Microporous Mesoporous Mater. 169, 180-184 (2013). https://doi.org/10.1016/j. micromeso.2012.11.012

56. H. Chen, F. Guo, Y.J. Liu, T.Q. Huang, B.N. Zheng, N. Ananth, Z. Xu, W.W. Gao, C. Gao, A defect-free principle for advanced graphene cathode of aluminum-ion battery. Adv. Mater. 29(12), 1605958 (2017). https://doi.org/10.1002/adma.201605958

57. X.B. Yang, J. Chen, Y.Q. Chen, P.J. Feng, H.X. Lai, J.T. Li, X.T. Luo, Novel $\mathrm{Co}_{3} \mathrm{O}_{4}$ nanoparticles/nitrogen-doped carbon composites with extraordinary catalytic activity for oxygen evolution reaction (OER). Nano-Micro Lett. 10(1), 15 (2017). https://doi. org/10.1007/s40820-017-0170-4

58. W. Zhang, X.F. Jiang, Y.Y. Zhao, A. Carne-Sanchez, V. Malgras et al., Hollow carbon nanobubbles: monocrystalline MOF nanobubbles and their pyrolysis. Chem. Sci. 8(5), 3538-3546 (2017). https://doi.org/10.1039/c6sc04903f

59. S. Kim, W.J. Dong, S. Gim, W. Sohn, J.Y. Park, C.J. Yoo, H.W. Jang, J.-L. Lee, Shape-controlled bismuth nanoflakes as highly selective catalysts for electrochemical carbon dioxide reduction to formate. Nano Energy 39, 44-52 (2017). https://doi.org/10. 1016/j.nanoen.2017.05.065

60. X.J. Wang, L.J. Wang, B.K. Chen, J. Yao, H.Y. Zeng, MOFs as reactant: in situ synthesis of $\mathrm{Li}_{2} \mathrm{ZnTi}_{3} \mathrm{O}_{8} @ \mathrm{C}-\mathrm{N}$ nanocomposites as high performance anodes for lithium-ion batteries. J. Electroanal. Chem. 775, 311-319 (2016). https://doi.org/10.1016/j. jelechem.2016.06.024

61. J.S. Meng, C.J. Niu, L.H. Xu, J.Y. Li, X. Liu et al., General oriented formation of carbon nanotubes from metal-organic frameworks. J. Am. Chem. Soc. 139(24), 8212-8221 (2017). https://doi.org/10.1021/jacs.7b01942

62. M. Jiang, X.P. Cao, D.D. Zhu, Y.X. Duan, J.M. Zhang, Hierarchically porous $\mathrm{N}$-doped carbon derived from ZIF-8 nanocomposites for electrochemical applications. Electrochim. Acta 196, 699-707 (2016). https://doi.org/10.1016/j.electacta.2016.02.094

63. S. Li, P. Xue, C. Lai, J.X. Qiu, M. Ling, S.Q. Zhang, Pseudocapacitance of amorphous $\mathrm{TiO}_{2} @$ nitrogen doped graphene composite for high rate lithium storage. Electrochim. Acta 180, 112-119 (2015). https://doi.org/10.1016/j.electacta.2015.08.099

64. Z.A. Zhang, C.K. Zhou, L. Huang, X.W. Wang, Y.H. Qu, Y.Q. Lai, J. Li, Synthesis of bismuth sulfide/reduced graphene oxide composites and their electrochemical properties for lithium ion 
batteries. Electrochim. Acta 114, 88-94 (2013). https://doi.org/ 10.1016/j.electacta.2013.09.174

65. X. Zhang, H. Liu, S. Petnikota, S. Ramakrishna, H.J. Fan, Electrospun $\mathrm{Fe}_{2} \mathrm{O}_{3}$-carbon composite nanofibers as durable anode materials for lithium ion batteries. J. Mater. Chem. A 2(28), 10835-10841 (2014). https://doi.org/10.1039/c3ta15123a

66. Y.L. Li, M.A. Trujillo, E. Fu, B. Patterson, L. Fei, Y. Xu, S.G. Deng, S. Smirnov, H.M. Luo, Bismuth oxide: a new lithium-ion battery anode. J. Mater. Chem. A 1(39), 12123-12127 (2013). https://doi.org/10.1039/C3TA12655B

67. Y.B. Zhao, A. Manthiram, High-capacity, high-rate Bi-Sb alloy anodes for lithium-ion and sodium-ion batteries. Chem. Mater. 27(8), 3096-3101 (2015). https://doi.org/10.1021/acs.chemmater. $5 \mathrm{~b} 00616$

68. S.Q. Chen, L.F. Shen, P.A. van Aken, J. Maier, Y. Yu, Dualfunctionalized double carbon shells coated silicon nanoparticles for high performance lithium-ion batteries. Adv. Mater. 29(21), 1605650 (2017). https://doi.org/10.1002/adma.201605650

69. P. Wang, X.B. Lou, C. Li, X.S. Hu, Q. Yang, B.W. Hu, One-pot synthesis of Co-based coordination polymer nanowire for Li-ion batteries with great capacity and stable cycling stability. NanoMicro Lett. 10(2), 19 (2017). https://doi.org/10.1007/s40820-0170177-X

70. Y.C. Lin, Q.J. Zhang, C.C. Zhao, H.L. Li, C.L. Kong, C. Shen, L. Chen, An exceptionally stable functionalized metal-organic framework for lithium storage. Chem. Commun. 51(4), 697-699 (2015). https://doi.org/10.1039/c4cc07149b

71. J. Liu, Y.R. Wen, P.A. van Aken, J. Maier, Y. Yu, Facile synthesis of highly porous $\mathrm{Ni}-\mathrm{Sn}$ intermetallic microcages with excellent electrochemical performance for lithium and sodium storage. Nano Lett. 14(11), 6387-6392 (2014). https://doi.org/10. $1021 / \mathrm{n} 15028606$

72. J. Ming, M.L. Li, P. Kumar, A.-Y. Lu, W. Wahyudi, L.-J. Li, Redox species-based electrolytes for advanced rechargeable lithium ion batteries. ACS Energy Lett. 1(3), 529-534 (2016). https://doi.org/10.1021/acsenergylett.6b00274

73. X.L. Xu, Z.D. Hao, H. Wang, J.B. Liu, H. Yan, Mesoporous carbon derived from Zif- 8 for improving electrochemical performances of commercial $\mathrm{LiFePO}_{4}$. Mater. Lett. 197, 209-212 (2017). https://doi.org/10.1016/j.matlet.2017.02.093 